studied. Good yields of ammonia were obtained from sodium cyanide by steaming at 50 lbs. pressure. A quantitative yield was obtained at $2001 \mathrm{bs}$.

The hydrolysis of ferrocyanides proceeded very slowly. A maximum yield of 46 per cent was obtained by steaming $4 \%$ hrs. at a pressure of 300 to 330 lbs.

With cyanized briquets, yields averaging over 90 per cent were obtained in 30 to $45 \mathrm{~min}$. by steaming at 300 to $330 \mathrm{lbs}$.

To obtain satisfactory results with steam at atmospheric pressure, a temperature of $600^{\circ} \mathrm{C}$. was necessary.

High temperatures were necessary to obtain good results with steam at low pressure. A temperature of $600^{\circ} \mathrm{C}$. with atmospheric pressure and $400^{\circ} \mathrm{C}$. with I oo lbs. pressure gave satisfactory results.

At the temperatures involved in the experiments with saturated steam there were no indications of side reactions, only formates and ammonia being produced.

\section{THE PREPARATION OF HEXANITRODIPHENYLAMINE AND ITS USE AS A BOOSTER FOR SHELL CHARGES ${ }^{1}$}

\section{By John Marshall}

Eastern laboratory, E. I. du Pont de Nemours \& Co., Chester, Pa.

Early after the entry of the United States into the war it became evident that the country's capacity for the manufacture of secondary detonating materials or "booster" explosives for high explosive shells was insufficient to provide for the extensive program planned by the Ordnance Department.

The material which had been used to the best advantage for this purpose and the one apparently preferred above all others was tetryl, or tetranitromethylaniline. Closely approaching this compound in value was tetranitraniline, though the latter had some disadvantages connected with its use on account of its questionable stability in the presence of moisture.

It was evident therefore that in order to compete with these compounds and at the same time supplement the available supply of secondary detonating agents, it would be necessary to produce a material of similar properties, i. e., high melting point, sensitiveness to detonation, and power as a detonator, and at the same time to produce it by some method whose simplicity would make it possible to compete with the relatively low prices of tetryl and TNA. Added to these requirements it was considered necessary to develop such a compound from sources other than toluene in order to conserve as far as possible the supply of this material.

A sirvey of the field indicated that the symmetrical hexanitrodiphenylamine would probably meet these requirements, though the literature was singularly vague on the properties of the material. A careful study was therefore made early in IgI8 on the manufacture and properties of this compound. The results in a large measure justified the hopes which

1 Presented at the 58th Meeting of the American Chemical Society, Philadelphia, Pa., September 2 to 6, 1919. had been felt, and it is probable that had the war continued, hexanitrodiphenylamine, or hexil, as it has been named, would have found a use as a substitute for tetryl in boosters for high explosive shells.

The first description of this compound was given in 1874 by P. T. Austen, who prepared it by nitration of picryl-p-nitraniline, and during the same year it was prepared by $\mathrm{Gnehm}^{2}$ by the nitration of diphenylamine. Neither of these methods can have any practical value on account of the high cost of the intermediates involved.

The synthesis described in a patent of the Chemische Fabrik Griesheim, ${ }^{3}$ and elaborated in $19 \mathbf{x}_{3}$ by $\mathrm{T}$. Carter, ${ }^{4}$ offered greater advantages, and it was this method which was settled on for development. This method as described by Carter depends on the reaction of $I, 2,4$-chlorodinitrobenzene with aniline to form dinitrodiphenylamine and aniline hydrochloride, with subsequent nitration by nitric acid in two stages to hexanitrodiphenylamine.

It should here be pointed out that a recent article by Messrs. Hoffman and Dame ${ }^{5}$ indicates that the Bureau of Mines was also interested in this subject, their work in a measure duplicating the early phases of our own work.

\section{PREPARATION OF DINITRODIPHENYIAMTNE}

The first preparation of dinitrodiphenylamine was made in accordance with Carter's procedure. This method consists of agitating two molecules of aniline with one molecule of chlorodinitrobenzene, the reaction beginning slowly at moderate temperature. There is at first a slow rise in temperature followed by a more energetic one, which carries the temperature to $125^{\circ}$ C., at which point the charge is drowned in water and extracted with water and dilute hydrochloric acid to remove excess aniline and by-product aniline hydrochloride.

In the laboratory excellent results were obtained with theoretical yields of a product melting at $149^{\circ}$ to $\mathrm{r}_{5}{ }^{\circ} \mathrm{C}$. When the process was tried on a larger scale, however, it was found difficult to control the temperature properly without drowning the charge before the completion of reaction, since the charge rapidly became so viscous that efficient agitation was out of the question.

The following more satisfactory method was then devised. ${ }^{B}$ Two molecules of aniline and one molecttle of chlorodinitrobenzene are added to three times their combined weight of water heated to $60^{\circ} \mathrm{C}$, and the mixture is agitated mechanically to form an emulsion. Steam is then introduced to raise the temperature to $80^{\circ} \mathrm{C}$, the reaction beginning during this heating, and coming to completion in one hour. The dinitrodiphenylamine precipitates in the form of thick clusters of red needles. Agitation at $80^{\circ} \mathrm{C}$. is continued one-half hour longer to insure complete solution of aniline hydrochloride, after which the charge

\footnotetext{
1 Ber., 7, 1248.

Ibid., 7, 1399

D. R. P. 86,295 , July 1885.

$4 Z$. ges. Schiess-Sprengstoffw., 1918, 205-251.

5 J. Am. Chem. Soc., 41 (1919), 1013.

U. S. Patent 1,309,580, July 8, 1919.
} 
is thrown on a filter, washed with dilute hydrochloric acid and water, and finally dried. 95 to roo per cent of theoretical yields are obtained of material melting at $148^{\circ}$ to $152^{\circ} \mathrm{C}$. The mother liquor from this process is available for recovery of aniline, and in several runs made in the laboratory recoveries of 85 per cent of the theory were made. This method gave perfect reaction control, and in addition yielded a product. in such form that it could be used at once for nitration. Several runs were then made on the roo $1 \mathrm{~b}$. scale with equally satisfactory results.

\section{PREPARATION OF TETRANITRODIPHENYLAMINE}

In the nitration of dinitrodiphenylamine thus prepared to the tetra stage, as before stated, the method of Carter involves the addition of dry dinitrodiphenylamine to nitric acid of approximately 40 per cent concentration at temperatures up to $90^{\circ} \mathrm{C}$. Any method of nitration involving the use of straight nitric acid is open to serious objections on account of excessive consumption of nitric acid and the necessity for using enameled equipment; and in addition to these objections it was found on trial of Carter's method that the nitration was liable at times to serious and almost uncontrollable foaming.

Carter's article makes the definite statement that a mixed nitric-sulfuric acid cannot be used for this nitration on account of the insolubility of dinitrodiphenylamine in sulfuric acid, but since the claim appeared unreasonable, a series of experiments was instituted on the use of mixed acid for nitration. After considerable investigation it was found that the nitration could be carried out satisfactorily by the addition of dry dinitrodiphenylamine at $70^{\circ} \mathrm{C}$. to 3.5 to 4 parts of a mixed acid containing 30 to 45 per cent $\mathrm{HNO}_{3}$ and 50 to 40 per cent $\mathrm{H}_{2} \mathrm{SO}_{4}$, followed by raising the temperature to $80^{\circ}$ to $90^{\circ}$ until evolution of $\mathrm{NO}_{2}$ was at a minimum. The nitration charge was then cooled and filtered for removal of the spent acid. The product of this nitration was a brownish yellow amorphous material, containing small percentages of higher nitration products, and was found to be in such condition that it could be used directly for the final nitration.

\section{NITRATION OF TETRANITRODIPHENYLAMTNE TO HEXANITRODIPHENYLAMINE}

Carter's procedure for the final nitration also involves the use of straight nitric acid, tetranitrodiphenylamine being added at $40^{\circ}$ to $70^{\circ} \mathrm{C}$. to a 90 per cent nitric acid, with final heating at $90^{\circ} \mathrm{C}$, followed by cooling and filtration. The product from this method consisted of a finely divided, almost amorphous material which dusted badly, and consequently involved danger of poisoning in handling.

It was found on experimenting that mixed acid could be used with satisfaction at this stage also, and that the character of the product could be varied at will from the amorphous form to the crystalline form by varying the proportion of nitric to sulfuric acid. For example, by the use of a mixed acid containing 25 per cent $\mathrm{HNO}_{3}$ and 70 to 75 per cent $\mathrm{H}_{2} \mathrm{SO}_{4}$, an amorphous product was obtained, as compared with a distinctly crystalline product when an acid containing 60 per cent $\mathrm{HNO}_{3}$ and 40 per cent $\mathrm{H}_{2} \mathrm{SO}_{4}$ was used. As a crystalline product is the more desirable, an acid of the last noted composition was finally used.

The final procedure consisted of adding the acid tetranitrodiphenylamine to 3.75 parts mixed acid at $70^{\circ} \mathrm{C}$., followed by one hour's heating at $90^{\circ} \mathrm{C}$., cooling to room temperature and filtering. The product thus obtained was a distinctly crystalline, yellow, free running material, melting sharply with decomposition at a temperature between $238.5^{\circ}$ and $239.5^{\circ} \mathrm{C}$.

This procedure, for both the tetra- and the hexastage nitrations, was also studied thoroughly on the Ioo lb. scale, with entirely satisfactory results. Yields of 86 per cent of the theory were obtained, this point duplicating the restult of the nitration with straight nitric acid. Spent acid recoveries throughout were very good and the spent acid composition was such that it could be handled in iron. The following are specimen analyses of the spent acid from the two stages:

\begin{tabular}{|c|c|c|}
\hline & $\begin{array}{l}\text { TETRA-STAGE } \\
\text { SPENT ACID } \\
\text { Per cent }\end{array}$ & $\begin{array}{c}\text { HEXA-STAGE } \\
\text { SPENT ACID } \\
\text { Per cent }\end{array}$ \\
\hline$\ldots \ldots \ldots$ & 14.28 & 33.62 \\
\hline $\mathrm{H}_{2} \mathrm{SO}_{4} \ldots \ldots \ldots \ldots \ldots \ldots \ldots$ & 50.95 & 40.03 \\
\hline $\mathrm{HNOSO}_{4} \ldots \ldots$ & 7.45 & 11.30 \\
\hline $\mathrm{H}_{2} \mathrm{O} \ldots \ldots \ldots \ldots$ & 26.13 & 14.16 \\
\hline Ether soluble........ & 1.07 & 0.89 \\
\hline
\end{tabular}

PREPARATION OF HEXANITRODIPHENYLAMINE BY COMPLETE NITRATION OF DINITRODIPHENYLAMINE WITH MIXED ACID

In the article by Hoffman and Dame ${ }^{1}$ the possibility is suggested of preparing hexanitrodiphenylamine by a one-stage nitration with mixed acid. This procedure was found to be possible by adding dinitrodiphenylamine to 3.75 parts of a mixed acid containing 60 per cent $\mathrm{HNO}_{3}$ and 30 per cent $\mathrm{H}_{2} \mathrm{SO}_{4}$ at temperatures up to $70^{\circ}$ to $80^{\circ} \mathrm{C}$. This results in the formation of the tetranitro compound. Two parts of fuming acid, analyzing 107 to $\mathrm{I} 08$ per cent $\mathrm{H}_{2} \mathrm{SO}_{4}$ are then carefully added at $80^{\circ}$ to $90^{\circ} \mathrm{C}$. to bring about nitration to the hexa stage and the charge is cooled after one hour, and filtered. 85 per cent of theoretical yields were obtained of amorphous material melting at $238^{\circ} \mathrm{C}$. Cost estimates indicated that the twostage process was preferable to this method, and it was not pursued further.

In this connection it was found that the use of acids of higher than 90 per cent acidity produced charring of dinitrodiphenylamine.

\section{NEUTRALIZATION OF FREE ACID IN HEXANITRODI- PHENYLAMINE}

In the work so far discussed no mention has been made of the methods used for freeing the hexanitrodiphenylamine from the free acid carried by the particles of the material.

No alkali can be used with hexanitrodiphenylamine for the reason that the material acts as an acid in the presence of alkalies, forming highly soluble salts, and it is therefore necessary to depend on the use of water for washing. It was found that there

1 Loc. cit. 
was great difficulty in completely purifying amorphous hexanitrodiphenylamine, but that the acid could be completely removed from the crystalline material by means of a drowning wash, followed by 2 or 3 onehour washes with boiling water, after which the product can be centrifuged and dried on trays at temperatures up to $80^{\circ} \mathrm{C}$.

EXPLOSIVE PROPERTIES OF HEXANITRODIPHENYLAMINE

While the foregoing work was being carried out on the preparation of hexanitrodiphenylamine, a thorough study was also made of the properties of the material in comparison with tetryl and tetranitraniline, the compounds which it was desired to replace, and with TNT.

The most important properties of an explosive for any purpose are unquestionably stability, sensitiveness to detonation, and explosive power. For use in a booster charge these items are especially important. The stability must be high, because of the high temperatures liable to occur in field service. The material must be sufficiently sensitive to give complete detonation with its primer charge, and, at the same time, must be sufficiently insensitive to eliminate danger from premature explosion. It must also be powerful enough to insure complete detonation of the bursting charge of the shell with a minimum size of booster charge.

As a test for stability, the Abel heat test has for a long time been recognized by the authorities as perhaps the most reliable. During the period of the war, however, the value of this test has been questioned many times when used for nitro compounds, and it is therefore being supplanted by other tests depending on the actual determinations of the products of decomposition of the nitro compound on heating. The most easily applied of this class of tests is the Obermuller, or gas evolution test, ${ }^{1}$ and this was developed in our laboratory to a fair degree of satisfaction.

It consists of heating a weighed portion of the material in question at $120^{\circ} \mathrm{C}$. in vacuo in a calibrated flask attached to a calibrated manometer: Pressure readings are taken every hour on the manometer, the increase in pressure being calculated back to cc. gas evolved per hour at the desired pressure.

Tested in this manner, hexil showed the following results, in comparison with other explosives:

\begin{tabular}{|c|c|c|}
\hline & M. P. & $\begin{array}{l}\text { Stability cc. } \\
\text { per hr. per } \mathrm{g} \text {. } \\
\text { at } 100 \mathrm{~mm} \text {. pressure }\end{array}$ \\
\hline Hexil $\ldots \ldots \ldots \ldots \ldots \ldots$ & 140.0 & 4.4 \\
\hline TNT $\ldots \ldots \ldots \ldots \ldots \ldots$ & $\begin{array}{l}77.3 \\
80.1\end{array}$ & $\begin{array}{l}3.6 \\
2.1\end{array}$ \\
\hline Tetryl $\ldots \ldots \ldots \ldots \ldots \ldots$ & $\begin{array}{l}127.0 \\
128.2 \\
129.0\end{array}$ & $\begin{array}{r}13.8 \\
2.6 \\
1.6\end{array}$ \\
\hline
\end{tabular}

It appears therefore that hexil has a stability close to that of TNT and tetryl, and it may be added that later routine tests on semi-works product indicated a normal stability somewhat better than tetryl of service quality.

IJ. Am. Chem. Soc., 30 (1908), 271.

\section{SENSITIVENESS OF HEXANITRODIPHENYLAMINE TO DETONATION}

The subject of sensitiveness to detonation has fortunately been more thoroughly studied in the past than has the subject of stability, and a number of recognized methods are at hand for this test.

Probably the most reliable of these methods is that in which determination is made of the minimum weight of priming charge to insure complete detonation. ${ }^{1}$ This test consists essentially of firing, with varying weights of fulminate-potassium chlorate priming mixture, a series of blasting caps loaded with equal weights of the material to be tested. The lead plate test described by Brunswig ${ }^{2}$ was used as an index to completeness of detonation.

The minimum priming charges for complete detonation of the several explosives compared were:

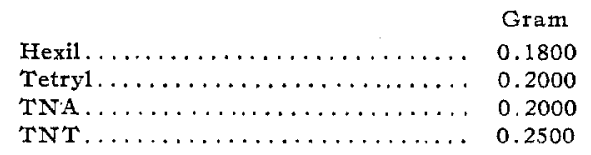

These tests showed therefore that hexil is slightly more sensitive to detonation than tetryl and TNA, and in addition indicated that the efficiency of hexil is practically the same as for tetryl and TNA, inasmuch as the perforations in the lead plates from all three compounds were comparable.

\section{SENSITIVENESS TO IMPACT}

The foregoing test for sensitiveness to detonation was supplemented by test for sensitiveness to impact and friction in order to gain an idea as to the safety of handling the material. Sensitiveness to impact was determined by the so-called drop test, in which $0.2 \mathrm{~g}$. of explosive, placed on an anvil between two plungers, is subjected to the fall of a $20-$ $\mathrm{kg}$. weight through a measured distance, the sensitiveness being expressed in terms of maximum height of drop at which no detonation occurred.

In this test, hexil gave no detonation at 5 in., while at the same height tetryl gave one detonation out of Io trials, TNA four detonations out of ro trials, and TNT no detonations. Hexil showed detonation at 6-in. drop, but TNT gave none until 25 in. drop was reached. It appears from this that hexil is somewhat less sensitive to shock than tetryl and TNA, and is possibly safer to handle.

\section{SENSITIVENESS TO FRICTION}

The sensitiveness to friction was studied in a pendulum friction apparatus such as was developed by the Bureau of Mines. ${ }^{3}$ In this test $7 \mathrm{~g}$. of explosive are placed on a bed plate and subjected to the friction of a $20-\mathrm{kg}$. weight attached to a pendulum swinging from a measured vertical height. Using a steel bed plate and a steel shoe, the pendulum falling from I.5 meters vertical height and swinging I 9 times before coming to rest, hexil, TNT, and tetryl gave no evidence of either local or general detonation. TNA, however, gave some local detonations.

1 Bureau of Mines, Technical Papers 125 and 145.

2 Brunswig, Monroe \& Kibler, "Explosives," p. 112.

8 Bureat of Mines, Bulletin 66, 15. 


\section{RIFLE BULLET TEST}

As a measure of sensitiveness to impact and friction combined, the rifle bullet test is recognized as most severe. This test consists of packing about I 1b. of the explosive to be tested into a $3 \cdot 5$-in. cube box of cardboard or tin, and firing into it from a distance of 30 yards with standard U. S. Army rifle (New Springfield). With hexil no detonations were obtained with cardboard boxes, but with tin boxes 7 detonations and one failure were obtained. With TNT no detonations were obtained with cardboard boxes. With tin boxes, the first and second hit in every case set fire to the TNT and the third hit gave a detonation. With tetryl and TNA detonations were obtained with both cardboard and tin boxes.

The preceding results on sensitiveness appeared to indicate that hexil is as sensitive as TNA and tetryl to the action of a primer, but with regard to mechanical shock or friction is more in a class with TNT and is therefore safer to handle.

\section{EXPLOSIVE POWER OF HEXANITRODIPHENYIAMINE}

The first tests which are usually applied in a determination of the explosive power of any compound are the ballistic mortar test and the determination of velocity. The ballistic mortar test ${ }^{1}$ is widely used and its details are well known. Briefly, the strength is determined in terms of some well-known explosive, for example, TNT, by firing such weights of the two explosives in the ballistic mortar as to give equal swings of the pendulum. Taking the strength of TNT as Io, the following results were obtained:

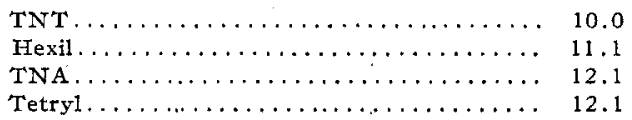

The strength of hexil is therefore midway between that of TNT and tetryl.

A determination of the velocity of detonation of hexil, made by the method of Dautriche, ${ }^{2}$ showed a velocity of $6898 \mathrm{~m} / \mathrm{sec}$. at I. 58 density, and 7 r 50 $\mathrm{m} / \mathrm{sec}$. at $\mathrm{I} .67$ density.

Similar figures from Marshall' for tetryl are:

$\begin{array}{cc}\text { Density } & \text { Velocity } \\ 1.53 & 7075 \mathrm{~m} / \mathrm{sec} . \\ 1.57 & 7155 \mathrm{~m} / \mathrm{sec} . \\ 1.63 & 721.5 \mathrm{~m} / \mathrm{sec} .\end{array}$

and for TNT, density r.59 and velocity 6649 $\mathrm{m} / \mathrm{sec}$.

It appears, therefore, that in explosive power and velocity, hexil is inferior to tetryl, but superior to TNT.

EFFECT AS A BOOSTER

It having been demonstrated that hexil has a satisfactory sensitiveness and power, it only remains to make a final comparison of hexil and tetryl as secondary detonators in their effect on the bursting charge of a shell. An index was given to this in the lead plate

\footnotetext{
1 Comey and Holmes, 8th Intern. Congr. Applied Chem., 25, 209.

2. Compt. rend., 143 (1906), 641.

3 "Explosives," 1915, 403.
}

test previously described in which it was found that while somewhat more sensitive than tetryl, hexil did not quite come up to tetryl as a booster material.

More conclusive results were given by a series of tests of the ability of tetryl and hexil, respectively, to detonate insensitive mixtures of 'TNT and iron oxide. In this test blasting caps were made up of 6.5 grains secondary charge (tetryl or hexil) and 5.3 grains primer (90-Io fulminate-chlorate mixture) and these caps used in firing a series of dynamite cartridges in which different mixtures of TNT and iron oxide had been handpacked. It was found that tetryl would give satisfactory detonation, of a mixture containing I 4 per cent iron oxide, while the limiting mixture for detonation with hexil contained only i I per cent iron oxide. While not equal to tetryl as a booster explosive, therefore, hexil shows to good advantage.

A final test of effect as a booster was made in comparison with other booster materials by fragmentation tests on a number of 3 -in. base detonating shells.

In this test the bursting charges of the shells consisted of cast refined TNT. Five each of the boosters were loaded with tetryl and TNT and ro each with hexil and TNA as secondary detonators. The fragmentations were made by dropping the shells from a height of $25 \mathrm{ft}$. into a steel bomb-proof chamber, the detonation being produced by the striking of the shell on a heavy iron anvil. The fragments were then collected, weighed to obtain percentage of recovery, sorted by sieving, and counted. The average results obtained were as follows:

\begin{tabular}{|c|c|c|c|c|}
\hline BOOSTER MATERIAL & TETRYL & TNT & TNA & IIEXIL \\
\hline Wt. booster charge, grams. & 28 & 27.5 & 27.5 & 27.5 \\
\hline Wt shell charge, grams... & 478 & 480 & 446 & 450 \\
\hline Wt. of metal in shell, grams. . & 6275 & 6261 & 6126 & 6156 \\
\hline Wt. of material recovered, grams.. & 6108 & 6116 & 6096 & 6112 \\
\hline $\begin{array}{c}\text { Per cent of material recovered, } \\
\text { total } \ldots \ldots \ldots \ldots \ldots \ldots \ldots \ldots\end{array}$ & 97.5 & 97.8 & 99.5 & 99.3 \\
\hline Number of fragments on 2 mesh.. & 178 & 161 & 188 & 179 \\
\hline $2-4 n$ & 1824 & 1679 & 1781 & 1651 \\
\hline$\ldots \ldots \ldots \ldots \ldots$ & 2002 & 1840 & 1969 & 1830 \\
\hline
\end{tabular}

From these results it appears that hexil is not so good as tetryl or TNA as a booster material, and is more nearly comparable with refined TNT for this purpose. It does, however, give a satisfactory order of detonation.

In connection with the use of hexil as a booster it is interesting to make note of the densities given by the compressed material. It was found impossible to make satisfactory blocks by the compression of crystalline hexil alone, but by the addition of $\mathbf{r}$ to 2 per cent of stearic acid excellent blocks resulted.

Using one per cent stearic acid as a binder, the results were as follows, the absolute density of crystalline hexil being I. 653 :

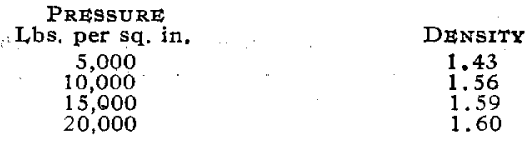


The best blocks were given by 10,000 lbs. and this was adopted as the standard pressure for preparing pellęts for boosters.

\section{CONCIUSIONS}

From the work which has been outlined it appears that the following conclusions were justified:

(r) Hexil as a booster material is superior to TNT, but somewhat inferior to tetryl and TNA.

(2) It is extremely stable and is safer to handle than either tetryl or TNA, and makes a satisfactory booster.

(3) It can be manufactured by a simple process from sources which would not conflict with TNT manufacture, and because of the excellent yields obtained, and the cheapness of intermediates for it, its material cost should be less than for either tetryl or TNA.

(4) On account of the simplicity of the process, the installation of a plant for its manufacture would be less expensive than for an extension of the manufacturing facilities for either tetryl or TNA.

(5) On account of the simplicity of operating methods, labor costs would be less than for either of the other materials.

\section{ACIDITY AND ACIDIMETRY OF SOILS. ${ }^{1}$ I-STUDIES OF THE HOPKINS AND PETTIT METHOD FOR DETERMINING SOIL ACIDITY}

\section{By Fenry G. Knight} Orlakoma Agricultural, and Mechantcal, College, Stilifwater,
Oflahoma

Received October 14, 1919

The Hopkins and Pettit method of determining soil acidity ${ }^{2}$ proposed in $\mathrm{r} 902$ is essentially as follows: I00 g. of soil are shaken in a bottle of $400 \mathrm{cc}$. capacity with $250 \mathrm{cc}$. of 5 per cent commercial common salt solution for $3 \mathrm{hrs}$. I $25 \mathrm{cc}$. of the clear liquid are taken off, boiled to expel carbon dioxide, and titrated using phenolphthalein as an indicator. The results are multiplied by 3 as a factor to determine the total amount of base required. Later a normal solution of potassium nitrate was substituted for the 5 per cent commercial common salt and the factor 2.5 recommended. The modified method is still the provisional method of the A. O. A. C. for determining the acidity of soils.

Veitch criticizes the Hopkins method upon the grounds that it indicates only the apparent need for lime or the most urgent need, and claims further that the acidity shown by this method is largely due to aluminates. $\mathrm{He}$ also notes that there is a great discrepancy between the Hopkins method and that proposed by himself ${ }^{5}$ upon soils high in organic matter.

1 From a thesis submitted to the faculty of the University of Illinois in partial fulfillment of the requirements for the degree of Doctor of Philosophy. Acknowledgment is made of many helpful suggestions and criticisms from Prof. C. G. Hopkins and Prof. A. H. Noyes. ,

2 Nineteenth Annual Proceedings, O. A. C., U. S. Dept. of Agr., Bureau of Chemistry, Bulletin 73 (1902), 114.

s U. S. Dept. of Agr., Bureau of Chemistry, Bulletin 107 (1908), 20; Hopkins, "Soil Fertility and Permanent Agriculture," 1910, 566.

I J. Am. Chem. Soc., 26 (1914), 637

- Ibid, 24 (1902), 1120.
Harris ${ }^{1}$ claims that the acidity shown by this method is due to selective ion absorption by the soil colloids, basing his views upon the fact that the acidity shown by the extract is dependent upon the character of the salts used. Freer ${ }^{2}$ also holds this view.. Truog ${ }^{3}$ strenuously combats the theory of colloidal absorption and brings evidence to support the view of Hopkins that the reaction is one of double decomposition between the acids or acid salts in the soil and the neutral salt solution. Parker ${ }^{4}$ concluded from analysis of extracts prepared by treating soils with potassium chloride and potassium acetate that the base was absorbed to a little greater extent than it was liberated by the soil and that the excess of the anion should be accounted for by the presence of the corresponding acid. Brogue ${ }^{5}$ states that it has been repeatedly proven that the base liberated by the soil is usually not merely equivalent to the base absorbed from the solution. Sullivan, ${ }^{6}$ Morse and Curry, ${ }^{7}$ Abbott, Conn and Smalley, ${ }^{8}$ Ruprecht, ${ }^{9}$ and others have noted. the presence of aluminum and iron in salt extracts from acid soils. Rice ${ }^{10}$ concludes from hydrogen-ion concentration studies upon 3 I soils using the indicator method of Sörensen ${ }^{11}$ that when so-called acid soils are shaken with salt solutions part of the cation of the salt is absorbed and an equivalent quantity of the base from the soil is given up to the solution.

It was to test the above points that the following investigations were made.

\section{EXPERIMENTAI}

Harris obtained different lime requirements for soils by repeated shaking with different salt solutions. These experiments were repeated in this laboratory using yellow-gray silt loam, and similar differences were obtained as was reported by Harris for different salts. As Hopkins claims that the reaction between the neutral salt solution and the soil is one of equilibrium, the end reaction would be practically impossible to realize by such a treatment. To overcome the objections which would arise from the above method provisions were made for forcing the salt solutions through the soil, so that the soil particles would be continually bathed by fresh solutions.

Twenty grams of yellow-gray silt loam $\mathrm{m}^{12}$ were placed upon a dry filter paper and the salt solution was allowed to filter through. The filtrate was boiled and treated with $0.04 N$ potassium hydroxide at room temperature using phenolphthalein as an indicator, with the results shown in Table I.

1 Michigan Agr. College and Station, Bulletin 19 (1914).

2 Penn. Dept. Agr., Bulletin 261 (1915), 106.

${ }^{8} J$. Phys. Chem., 20 (1916), 157.

4 This JourNaI, 6 (1914), 831.

5 J. Phys. Chem., 19 (1915), 665.

- U. S. Geol. Survey, Bulletin 312 (1907)

7 New Hampshire Agr. Station, Report 1906-08, 271.

8 Indiana Agr. Expt. Station, Bulletin 170 (1913).

- Mass. Agr. Expt. Station, Bulletin 161 (1915).

10 J. Phys. Chem., 20 (1916), 214.

11 Biochem. J., 21 (1909), 131; Walpole, Biochem., 5 (1911), 207; 8 (1914), 628

12 Sample No. 1. Subsoil from Southern Illinois. Lime requirement : Hopkins Method 4.2T., Veitch Method 5.6T., per acre of soil of 2,000,000 lbs. 